\title{
The Perceptions of Temporal Path Analysis of Learners' Self-regulation on Learning Stress and Social relationships in Junior High School
}

\author{
Hsiu-Ju Chang \\ Department of Education, National Chengchi University, Taiwan
}

Copyright (C) 2016 by authors, all rights reserved. Authors agree that this article remains permanently open access under the terms of the Creative Commons Attribution License 4.0 International License

\begin{abstract}
This research focus on the temporal path analysis of learning stress, test anxiety, peer stress (classmate relatedness), teacher relatedness, autonomy, and self-regulative performance in junior high school. Owing to the processes of self-determination always combines several negotiations with the interactive perceptions of personal experiences and social cognition network. However, the inexperience or experience of appraisal and coping processes of stress and anxiety usually frustrate individual's willingness, ambition, and self-regulation to learn more and go further. Two hundred fifty-five students (75 in Grade7; 106 in Grade8; 44 in Grade9) in $7^{\text {th }} \sim 9^{\text {th }}$ grade participated in this path analyses study. The results revealed the possible relationships among the autonomy, stress, anxiety, social relatedness, and self-regulation performance in self-reported cognitive activations. Path analyses showed that the self-regulation was effected by social care, social supports, and learning stress.
\end{abstract}

Keywords Self-determination, Learning Stress, Self-regulation

\section{Introduction}

Self-regulation refers to higher cognitive, motivational, and emotional processes that enable individuals to guide their goal-directed activities over time, including the modulation of cognition, affect, and behavior $[11,30]$ in the systematical oriented toward individual's attainments with their thoughts, feelings, stresses, and actions [30, 25, 24, 26, and 19] And learning processes are combined self-regulation with cognition, motivation, and emotion from individuals' learning environment for learners to control, cope, and react to learning processes. Consequently, individuals' meta-cognition, meta-motivation, and meta-emotion will not only be the productions or creations of environment interactions, but also be the resources or motivators of self-regulation learning $[10,11,12,13$, and 14]. This research is focused on the self-regulated learning processes at the junctions of stress, cognition, social care, social support, and test anxiety in less-structured learning environments. We want to focus on the sources of motivators to self-regulated learning processes, such as social and peer stress, cognition, social support, and anxiety in junior high school students. And Amabile [27] proposed a model of motivational synergy which presented the intrinsic and extrinsic motivation may interact the outcomes from work and environment. Furthermore, the extrinsic motivation may lack of self-determination [1, 2, and, 3] in individual's behaviors. In other words, behaviors were triggered by events of key persons or environmental atmosphere. Accordingly, individual's autonomy may take ownership by somebody or events with less self-determination processes in specific behaviors. Consequently, the behaviors may not be the intentions of individuals themselves but may be the interactions among key persons, peers, and environments. Owing to the behaviors should be work by individuals, the intrinsic and extrinsic motivations will be the main essential issues to be discussed. Oppositely, the autonomy and self-regulation performance will be intentions by individual himself to maintain individual's ownership in the behaviors which are more internalized into the self-concept than others. Self-regulative constructs, appraisal and coping [4], autonomy and self-regulation [5, 6, 7, 8, 9] performance, will be the cognitive activation and intrinsic motivation of individuals. These self-regulatory activities may mediate the relationships between individuals and the context, and their overall social relationships. In this research, self-regulation constructs adopts the social-cognitive perspective (classmate relatedness, teacher relatedness, and family supports) and autonomy, self-regulative performance that conceptualizes personality as the outcome of social context of self-determination theory and sensitive cognitive processes [15]. The social-regulative and self-regulative cognition network definitions of constructs and descriptions 
of cognitive determinations of individuals for self-regulation specifies how self-knowledge and social relationships influences appraisal and coping processes in stress and anxiety situations. And the social-regulative and self-regulative cognition network show that the architecture is compatible with both social-cognitive and trait perspectives. Next, we provide a general overview of empirical findings that links traits to individual differences in self-regulative processes and performance.

\section{Social and Self-regulative Cognition Network}

The social and self-regulated cognizing and learning network are the individual learners who are intended to or not to handle their meta-cognition, meta-motivation, and meta-emotion then shift to their goal-directed activities and learning behaviors. Social and self-regulated learning are interacted by other's or individual's metacognition (knowing about thinking), meta-motivation (knowing about willing), and meta-emotion (knowing about feeling) to raise strategic actions (planning, monitoring, and evaluating personal progress against a standard) with individual's desiring, willing, and ambitioning autonomously during learning processes. Self-regulation refers to enable individuals to guide their goal-directed activities over time with higher cognitive and motivational processes in modulation of cognition, affect, and behavior $[11,30]$ with their thoughts, feelings, stresses, and actions [25, 24, 26, and 19]. And self-regulated learning is the ability to control and handle one's cognitive processes [31]. Self-regulation and social-regulation in learning and teaching interactions may communicate and interact the competition, meta-motivation, meta-motivation and meta-cognition of individual learners which are based on sensory information and strategy modification autonomously and dynamically. The active and constructive processes are the essential issues of self-regulation for learners to plan, monitor, and control their own learning and teaching processes [7, 16, 17, 18, 19]. Self-regulation learning can be adopted in planning, monitoring, controlling, and evaluating individuals engage in learning circumstance [20, 21, and 22]. Furthermore, the social cognitive theory [23] mentioned that self-influence will motivate and regulate human behaviors extensively. And sub-functions of major self-regulative mechanism are self-monitoring, judgment, and self-reaction of one's behaviors which are based on individual's meta-cognition, meta-motivation, and meta-emotion to affective self-reactions. Consequently, the self-regulatory systems are the essential issues of causal-effect processes to make personal judgements and intentional behaviors interpersonally. Owing to learning is a complex task, several different aspects and characteristics of learners, instructors, and materials must be taken into consideration.
The social-regulative objectives are divided into classmate relatedness and teacher relatedness sub-objectives for detecting individual's social relatedness. In addition, the self-regulative (self-regulative performance and autonomy) is set to scaffold and communicate the appraisal and coping processes. The functions of social-regulative and self-regulative cognition network are to realize how self-knowledge influences appraisal and coping processes. Moreover, the autonomy, self-control, self-monitor, self-discipline, and self-efficacy are implied to support the learners to reach specific objectives with self-generate thinking, feeling, acting, monitoring, and evaluating processes. Individual's specific feedback, commitment, control, and confidence are interacted each other in self-regulation which can be used to clarify goals and reduce or remove uncertainty in task [28]. Furthermore, Pintrich [29] proposes four assumptions of self-regulation learning models as the followings: 1) active and constructive assumption; 2) potential for control assumption; 3) goal, criterion, or standard assumption; 4) activities are mediators between personal and contextual characteristics and actual achievement or performance. The designs adopted self-report questionnaires to cover the emotion, cognition, and motivation of social-regulative and self-regulative questionnaire were implemented in eight latent variables.

\section{Method}

\subsection{Social-regulative and Self-regulative Questionnaire}

Eight regulative constructs cover the emotion of social-regulative and self-regulative questionnaire were implemented in eight latent variables (class stress, classmate relatedness, self-regulative performance, classmate stress, autonomy, teacher relatedness, and teacher help). All scales were 4-point scales for self-report. A scale consisting of two to six items measured social-regulative and self-regulative concepts. The Cronbach's alpha internal consistency reliability was 0.88 . The Cronbach's alpha internal consistency reliability coefficients for the subscales course stress, peer stress, self-regulation, social care, and social support were $0.754,0.783,0.731,0.92$, and 0.913 , respectively. Nine $7^{\text {th }} \sim 9^{\text {th }}$ grade classes, with a total of 255 junior high school students, participated in the study. The values of Cronbach's alpha, AVE (Average Variance Extracted), composite reliability, R Square, communality, and discriminability of measurement model are showed in table 1.

In data analysis, the percentage of participants thought that their family $(80 \%)$ and classmate $(72 \%)$ were the major people could help and care about themselves. And the percentage of "participants feel anxious about good grade of classmate will he does not is $47 \%$. 
Table 1. The values of cronbach's alpha, ave (average variance extracted), composite reliability, R square, communality, and discriminability of measurement model

\begin{tabular}{|c|c|c|c|c|c|c|}
\hline & Cronbachs Alpha & AVE & Composite Reliability & R Square & Communality & Redundancy \\
\hline CourseStress & 0.754286 & 0.49508 & 0.828315 & & 0.495079 & \\
\hline PeerStress & 0.783704 & 0.463546 & 0.837615 & 0.183919 & 0.463545 & 0.079815 \\
\hline Self-Regulation & 0.731548 & 0.483991 & 0.823185 & 0.283424 & 0.483991 & 0.084029 \\
\hline SocialCare & 0.920765 & 0.718783 & 0.938555 & & 0.718783 & \\
\hline SocialSupport & 0.913839 & 0.667563 & 0.932662 & 0.393107 & 0.667563 & 0.262318 \\
\hline
\end{tabular}

Table 2. Correlation matrix for path analysis of eight construct

\begin{tabular}{|c|c|c|c|c|c|c|c|c|}
\hline & Mate Relate & Test Mate Stress & Learn Stress & Test Aniety & Performance & Autonomy & Tea Relate & Tea Support \\
\hline Mate Relate & 1 & & & & & & & \\
\hline Test Mate Stress & $.226^{* *}$ & 1 & & & & & & \\
\hline Learn Stress & 0.026 & $.147 *$ & 1 & & & & & \\
\hline Test Aniety & 0.093 & 0.118 & -0.082 & 1 & & & & \\
\hline Performance & $.188^{* *}$ & $.494 * *$ & 0.056 & 0.088 & 1 & & & \\
\hline Autonomy & 0.051 & $.244 * *$ & 0.091 & 0.057 & $.351 * *$ & 1 & & \\
\hline Tea Relate & 0.001 & $.134 *$ & 0.043 & 0.095 & $.203 * *$ & $.331 * *$ & 1 & \\
\hline Tea Support & $-.133 *$ & 0.007 & -0.102 & 0.076 & $.180^{* *}$ & $.323 * *$ & $.620 * *$ & 1 \\
\hline
\end{tabular}

\subsection{Path Analysis of Social-regulative and Self-regulative Constructs}

We find the loading factors are higher than 0.5 , the reliabilities are higher than 0.7 , and the average variance extracted values are higher than 0.5 . And the discriminant validities are verified by the square root of average variance extracted values for each construct. In discriminant validity the correlations of the specific construct are greater than all other constructs (Fornell \& Larcker, 1981). Hypotheses 1: classmate relatedness, classmate stress and autonomy were mediator class stress and self-regulative performance. Hypotheses 2: the learning stress may positive effect on test anxiety. Hypotheses 3: the learning stress may positive effect on self-regulation. Hypotheses 4: the supports of classmates, teachers, and parents may effect on self-regulation. Hypotheses 5: the care of others may effect on self-regulation. The results were showed in figure 2 .

\section{Results}

\subsection{Path Analysis}

In order to test these mediational hypotheses, for each of the three outcome variables the path analysis was performed. Table 2 illustrated the correlation matrix of eight constructs. In figure 1, path analyses, the fit indices were acceptable (all RMSEA < .10). In analysis, the perceptions of classmate relatedness (MateRelate), classmate stress (TestMateStress) and autonomy were mediators class stress and self-regulative performance. We may infer that the more work hard classmate existed, the more peer stress may be happened. It means that individual learner may feel stress while the classmates work hard or maintain the good performances in classroom. And the individual autonomy are correlated to the relationships and supports of instructors. We may infer that learners have more teacher supports or good relations with teacher will encourage individual to handle the learning processes and enhance his learning performances in learning processes.

Figure 1 illustrates the interactions of the classmate and teacher relatedness to effect the self-regulation. The model analysis is based on LISREL 8.8 which is software for structural equation modeling now includes statistical methods for complex survey data. Goodness of Fit Statistics are the follows: Degrees of Freedom $=112$, Minimum Fit Function Chi-Square $=200.87(\mathrm{P}=0.00)$, Normal Theory Weighted Least Squares Chi-Square $=209.41(\mathrm{P}=0.00)$, Estimated Non-centrality Parameter $(\mathrm{NCP})=97.41,90$ Percent Confidence Interval for $\mathrm{NCP}=(60.52 ; 142.12)$, Population Discrepancy Function Value $(\mathrm{F} 0)=0.43,90$ Percent Confidence Interval for $\mathrm{F} 0=(0.27 ; 0.63)$, Root Mean Square Error of Approximation (RMSEA) = $0.062<0.08,90$ Percent Confidence Interval for RMSEA = $(0.049 ; 0.075)$, P-Value for Test of Close Fit (RMSEA S $0.05)=0.062<0.08,90$ Percent Confidence Interval for $\mathrm{ECVI}=(1.14 ; 1.50)$, ECVI for Saturated Model $=1.37$, ECVI for Independence Model $=12.66$, Independence AIC = 2835.50, Model AIC $=291.41$, Saturated AIC $=306.00$, Independence CAIC $=2910.57$, Model CAIC $=472.47$, Saturated CAIC $=981.66$, Non-Normed Fit Index $(\mathrm{NNFI})=$ $0.96>0.9$, Parsimony Normed Fit Index $(\mathrm{PNFI})=0.76>0.5$, Comparative Fit Index $(\mathrm{CFI})=0.97>0.9$, Incremental Fit Index $(\mathrm{IFI})=0.97>0.9$, Relative Fit Index $(\mathrm{RFI})=0.91>0.9$, Root Mean Square Residual (RMR) $=0.063<0.05$, Standardized RMR $=0.063$, Goodness of Fit Index $(\mathrm{GFI})=$ 0.90, Adjusted Goodness of Fit Index $(\mathrm{AGFI})=0.86<0.9$, Parsimony Goodness of Fit Index $(\mathrm{PGFI})=0.66>0.5$; And figure 1 illustrated the social support, learn stress, test anxiety, and self-regulation are interacted each other. 


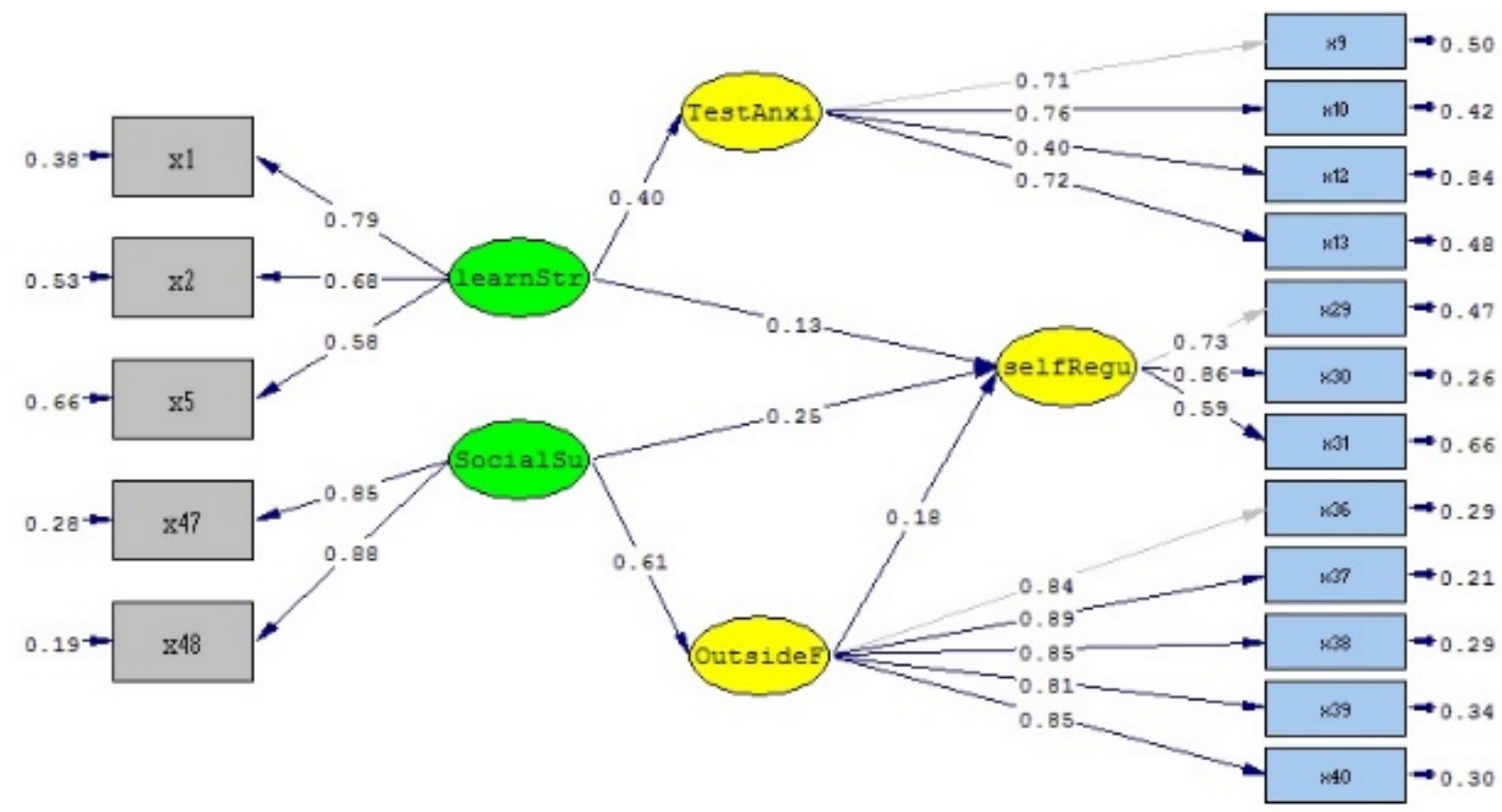

Chi-square=209.41, df=112, p-value=0.00000, RMSEA $=0.062$

Figure 1. the social support, learn stress, test anxiety, and self-regulation are interacted each other.

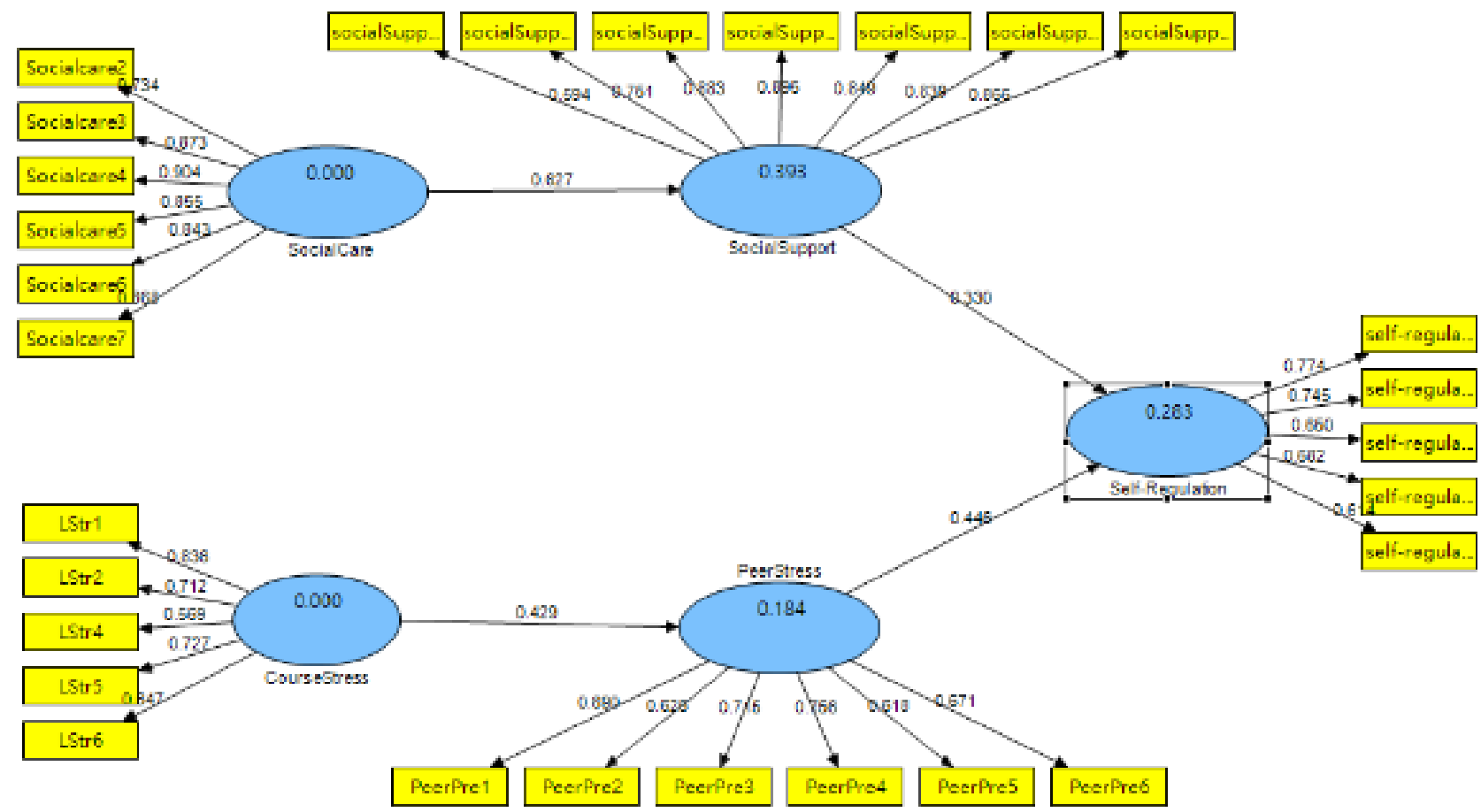

Figure 2. The path analysis of relationships and interactions among the course stress, social care, peer stress, social support, and self-regulative performance. 
The peer relatedness and teacher helps may make positive and negative impact on individual autonomy. It may proof the teenagers want to maintain the good relationships with peers but less anticipation to maintain good relationship with teachers. The model analysis is based on partial least squares (PLS) which is an exploration or construction technology to predict the causal model form the latent variables for reasoning and comparing. And the causal model maintains the relationships among the latent variables and constructs. We find a good result of convergent and discriminant validity in table 3 . All test of constructs supported convergent validity of the scales.

Table 3. The cross loading table of constructs

\begin{tabular}{|l|l|l|l|l|l|}
\hline & CourStress & PeerStress & SocialCare & Self-Reg & SocSup \\
\hline CourStr1 & $\mathbf{0 . 8 3 6 0 1}$ & 0.39331 & -0.02521 & 0.19616 & -0.02654 \\
\hline CourStr2 & $\mathbf{0 . 7 1 1 5 4}$ & 0.21789 & -0.03504 & 0.10588 & -0.05890 \\
\hline CourStr4 & $\mathbf{0 . 5 6 8 7 3}$ & 0.13927 & -0.02366 & 0.01101 & -0.08111 \\
\hline CourStr5 & $\mathbf{0 . 7 2 6 6 2}$ & 0.31609 & 0.02665 & 0.23027 & -0.06960 \\
\hline CourStr6 & $\mathbf{0 . 6 4 7 1 3}$ & 0.33305 & 0.04176 & 0.25455 & -0.04039 \\
\hline PeerPre1 & 0.38564 & $\mathbf{0 . 6 8 9 6 9}$ & 0.05939 & 0.17486 & -0.10776 \\
\hline PeerPre2 & 0.26919 & $\mathbf{0 . 6 2 4 5 2}$ & 0.09183 & 0.15433 & -0.07216 \\
\hline PeerPre3 & 0.32674 & $\mathbf{0 . 7 1 5 0 2}$ & 0.12221 & 0.47801 & 0.01201 \\
\hline PeerPre4 & 0.31760 & $\mathbf{0 . 7 5 6 1 9}$ & 0.11584 & 0.35906 & -0.00533 \\
\hline PeerPre5 & 0.17745 & $\mathbf{0 . 6 1 7 9 2}$ & 0.01337 & 0.12136 & -0.11140 \\
\hline PeerPre6 & 0.20436 & $\mathbf{0 . 6 7 1 3 2}$ & -0.01874 & 0.23353 & -0.14636 \\
\hline SocCare2 & 0.10672 & 0.13201 & $\mathbf{0 . 7 3 4 1 4}$ & 0.34200 & 0.49016 \\
\hline SocCare3 & -0.05232 & 0.08642 & $\mathbf{0 . 8 7 2 5 1}$ & 0.28825 & 0.51817 \\
\hline SocCare4 & 0.03996 & 0.15308 & $\mathbf{0 . 9 0 4 3 1}$ & 0.30377 & 0.57521 \\
\hline SocCare5 & 0.01088 & 0.15310 & $\mathbf{0 . 8 5 4 7 3}$ & 0.29673 & 0.51855 \\
\hline SocCare6 & -0.02406 & 0.00005 & $\mathbf{0 . 8 4 2 7 7}$ & 0.18725 & 0.48296 \\
\hline SocCare7 & -0.06489 & 0.03445 & $\mathbf{0 . 8 6 8 2 6}$ & 0.22029 & 0.58941 \\
\hline Self-Reg1 & 0.21156 & 0.30983 & 0.20846 & $\mathbf{0 . 7 7 4 3 6}$ & 0.19961 \\
\hline Self-Reg2 & 0.24956 & 0.41404 & 0.15905 & $\mathbf{0 . 7 4 5 4 0}$ & 0.12332 \\
\hline Self-Reg3 & 0.17910 & 0.27438 & 0.10137 & $\mathbf{0 . 6 5 0 4 1}$ & 0.11230 \\
\hline Self-Reg4 & 0.19860 & 0.28181 & 0.33477 & $\mathbf{0 . 6 8 2 0 4}$ & 0.24671 \\
\hline Self-Reg7 & 0.03426 & 0.14908 & 0.30618 & $\mathbf{0 . 6 1 3 6 0}$ & 0.34458 \\
\hline socSup1 & -0.08094 & -0.04948 & 0.35284 & 0.23309 & $\mathbf{0 . 5 9 3 5 6}$ \\
\hline socSup2 & -0.05969 & -0.08360 & 0.47733 & 0.27858 & $\mathbf{0 . 7 5 0 7 4}$ \\
\hline socSup3 & -0.08308 & -0.10257 & 0.54346 & 0.23999 & $\mathbf{0 . 8 8 3 4 6}$ \\
\hline socSup4 & -0.05129 & -0.02464 & 0.57406 & 0.28496 & $\mathbf{0 . 8 9 5 4 0}$ \\
\hline socSup5 & -0.01561 & -0.02353 & 0.52335 & 0.24199 & $\mathbf{0 . 8 4 9 0 6}$ \\
\hline socSup6 & -0.09217 & -0.12472 & 0.53205 & 0.14846 & $\mathbf{0 . 8 3 8 5 1}$ \\
\hline socSup7 & -0.02671 & -0.06803 & 0.55035 & 0.24755 & $\mathbf{0 . 8 6 6 4 7}$ \\
\hline
\end{tabular}

In figure 1, the path analysis showed the interaction relationships between self-regulation, course stress, peer stress, social care, and social support. The path coefficients of social care $\rightarrow$ social support, social support $\rightarrow$ self-regulation, course stress $\rightarrow$ peer stress, and peer stress $\rightarrow$ self-regulation are $0.627,0.330,0.429$, and 0.446 with statistically significant. It means that not only the interactions between inner intrinsic or extrinsic motivations, but also the communications between intrinsic and extrinsic motivations. And this research also showed that the path relationship of extrinsic compensation -> intrinsic challenge with high path coefficient, 0.716876 . It suggests the teaching strategies of extrinsic compensation that may promote individual's intrinsic challenge.

\section{Conclusions}

Typically the Perceptions of Temporal Path Analysis of Learners' Self-regulation on Learning Stress and Social relationships is intended to motivate or reinforce learning processes for better teaching and learning performance. And he effects of self-reguation were not merely to understand the meanings for passing and reaching the learning goals, but also to enhance and communicate the possible interactions and communications for evaluating and creating possible processes into high cognitive processes. In situated learning environment, the situated learning regulation is involved the self-motivation, self-motion, self-cognition, social behaviors, and environmental interactions which is embedded within teaching and learning activities, contexts, and classroom atmosphere. Consequently, the s situated learning regulation are not merely to maintain the intentional purposes with teaching or learning strategies, but also the unintentional events with interactions among the instructor, learner, and environment. The resources of motivators or stressors may lead good or bad performances during learning processes. The peer stressor and peer interactions will be the contributors of individuals' stressors to effect on learning outcomes. And different relatedness may positive or negative to effect on individual autonomy and self-regulation learning behaviors. And the individual self-regulation learning behaviors will lead and effect on individual's learning performances. These studies want to analyze the relations among the elements of learning stress, test anxiety, classmate relatedness, teacher relatedness, autonomy, self-regulative performance, and social supports. The results revealed differences in students' experience of the peer stress, test anxiety, social supports, and self-regulation performance in self-reported cognitive activation. Consequently, the self-regulation and social-regulation may be the positive reasons to enhance and support the learning processes for individuals to learn well and go further confidently. 


\section{REFERENCES}

[1] E. L. Deci, R. M. Ryan, Intrinsic motivation and self-determination in human behavior. New York: Plenum, 1985.

[2] E. L. Deci, R. M. Ryan, The "what" and "why" of goal pursuits: Human needs and the self-determination of behavior. Psychological Inquiry, 11, 227-268, 2000a.

[3] R. M. Ryan, E. L. Deci, Self-determination theory and the facilitation of intrinsic motivation, social development, and well-being. American Psychologist, 55, 68-78, $2000 \mathrm{~b}$.

[4] R. S. Lazarus, S. Folkman, Stress, appraisal and coping. New York: Springer, 1984.

[5] L. L. Aubrey, J. M. Brown, W. R .Miller, Psychometric properties of a self-regulation questionnaire (SQ.). Alcoholism: Clinical \& Experimental Research, 18, 429, 1994.

[6] J. M. Brown, W. R.Miller, L. A. Lawendowski, The Self-Regulation Questionnaire. In L. VandeCreek \& T. L. Jackson (Eds.), Innovations in clinical practice: A source book (Vol. 17, pp. 281-289). Sarasota, FL: Professional Resource Press, 1999.

[7] P. R. Pintrich, The role of goal orientation in self-regulated learning. In Boekaerts, M., Pintrich, P. R., and Zeidner, M. (eds.), Handbook of Self-Regulation, Academic Press,San Diego, CA, pp. 451-502. 2000.

[8] B. J. Zimmerman, M. Martinez-Pons, Development of a structured interview for assessing student use of self-regulated learning strategies. American Educational Research Journal, 23, 614-628, 1986.

[9] B.J. Zimmerman, "Dimensions of Academic Self-Regulation: A Conceptual Framework for Education.” In Self-Regulation of Learning and Performance: Issues and Educational Applications, eds. D.H. Schunk \& B.J. Zimmerman, 3-24. Hillsdale, NJ: Erlbaum, 1994.

[10] D. L. Butler, P. H. Winne, Feedback and Self-Regulated Learning: A Theoretical Synthesis. Review of Educational Research, 65(3), 245 -281, 1995.

[11] B.J. Zimmerman, A social cognitive view of self-regulated learning and academic learning. Journal of Educational Psychology, 81(3), 329-339, 1989.

[12] B. J. Zimmerman, Academic studying and the development of personal skill: A self-regulatory perspective. Educational Psychologist, 33, 73-86, 1998a

[13] B. J. Zimmerman, Developing self-fulfilling cycles of academic regulation: An analysis of exemplary instructional models. In D. H. Schunk \& B.J. Zimmerman (Eds.), Self-regulated learning: From teaching to self-reflective practice (pp. 1-19). New York: Guilford Press, 1998b.

[14] B. J. Zimmerman, Attaining self-regulation: A social cognitive perspective. In M.Boekaerts, P.R. Pintrich, \& M. Zeidner (Eds.), Handbook of self-regulation: Theory research, and applications (pp. 13-39). San Diego, CA: Academic Press, 2000.

[15] V. L. Schwean, D. H. Saklofskr, A cognitive-social description of exceptional children, In D. H. Saklofske, \& M.
Zeidnor (Eds.), International handbook of personality and intelligence. New York: Plenum, 1995.

[16] P. H. Winne, A. F. Hadwin, Studying as self-regulated learning. In D. J. Hacker, J., 1998.

[17] B. J. Zimmerman, Self-regulated learning and academic achievement: an overview. Educational Psychologist, 25, 3-17, 1990 .

[18] P. H. Winne, Self-regulated learning viewed from models of information processing. In B. J. Zimmerman, \& D. H. Schunk (Eds.) (1989), Self-regulated learning and academic achievement: Theoretical perspectives, 153-189. Mahwah, NJ: Lawrence Erlbauw, 2001.

[19] B. J. Zimmerman, D. H. Schunk, Reflections on theories of self-regulated learning and academic achievement. In B. J. Zimmerman \& D. H. Schunk (Eds.), Self-regulated learning and academic achievement: Theoretical perspectives. Mahwah, NJ: Lawrence Erlbaum Associates, 2001.

[20] K.W. Thiede, J. Dunlosky, Toward a general model of self-regulated study: An analysis of selection of items for study and self-paced study time. Journal of Experimental Psychology: Learning, Memory, and Cognition, 25, 1024-1037, 1999.

[21] J. D. Karpicke, Metacognitive control and strategy selection: Deciding to practice retrieval during learning. Journal of Experimental Psychology: General, 138, 469-486, 2009.

[22] J. Metcalfe, Metacognitive judgments and control of study. Current Directions in Psychological Science, 18, 159-163, 2009.

[23] A. Bandura, Social cognitive theory of self-regulation. Organizational Behavior and Human Decision Processes, 50, 248-287, 1991

[24] D.H. Schunk, B.J. Zimmerman, Self-regulation of learning and performance: Issues and educational applications. Hillsdale, NJ: Lawrence Erlbaum Associates, 1994.

[25] M. Boekaerts, P. R.Pintrich, M. Zeidner, (Eds.).. Handbook of self-regulation. San Diego: Academic Press, 2000.

[26] D. H. Schunk, B. J. Zimmerman, (Eds.). Self-regulated learning: from teaching to self-reflective practice. New York: Guilford Press, 1998.

[27] T. M. Amabile, Motivational synergy: Toward new conceptualizations of intrinsic and extrinsic motivation in the workplace. Human Resource Management Review, 3, 185-201, 1993.

[28] J. Hattie, H. Timperley, The power of feedback. Review of Educational Research, 77(1), 81-112, 2007.

[29] P. R. Pintrich, A conceptual framework for assessing motivation and self-regulated learning in college students. Educational Psychology Review, 16, 385-417, 2004.

[30] P. Karoly, Mechanisms of self-regulation: a systems view. Annual Review of Psychology, 44, 23-52, 1993.

[31] T. Sitzmann, G. Yeo, A meta-analytic investigation of the within-person self-efficacy domain: Is self-efficacy a product of past performance or a driver of future performance? Personnel Psychology, 66, 531-568, 2013. 